\title{
Facilitation of Kindled Seizures in Rats Fed Choline-Supplemented Diets
}

\author{
Kevin McCann, Donald P. Cain and Diana J. Philbrick
}

\begin{abstract}
SUMMARY: Different groups of rats were maintained on choline-deprived (CD), choline-supplemented (CS) or standard rat chow diets beginning at a body weight of approximately $100 \mathrm{~g}$, and electrically kindled in the amygdala beginning not less than 40 days later. The CS group kindled significantly faster than the CD group, whereas the CD and chow-fed groups did not differ in their rate of kindling. This result is consistent with both the known effects of the dietary manipulation of choline on brain acetylcholine level, and the idea that acetylcholine has a role in amygdaloid kindling.
\end{abstract}

RÉSUMÉ: Nous avons maintenu différents groupes de rats à des diètes variées: choline-déficiente (CD), choline-supplémentée (CS) ou régulières, à partir d'un poids d'environ $100 \mathrm{~g}$. Ces animaux ont reçu un kindling électrique dans l'amygdale un minimum de 40 jours plus tard. Le groupe Cs manifestait le kindling significativement plus vite que le groupe CD, alors qu'il n'y avait pas de différence dans le taux de kindling entre le groupe CD et celui recevant la nourriture régulière. Ces résultats sont compatibles avec nos connaissances sur l'effet de la choline sur la concentration d'acétylcholine cérébrale, et avec la proposition que l'acétylcholine a un rôle à jouer dans le kindling de l'amygdale.

Can. J. Neurol. Sci. 1983; 10:47-49

The manipulation of diet has been used in an effort to treat a variety of medical disorders (Fernstrom, 1981). Two such examples are Alzheimer's disease and tardive dyskinesia where attempts have been made to ameliorate symptoms by the increased dietary intake of precursors of acetylcholine (Bartus et al., 1982; Davis et al., 1975). This treatment is based upon the finding that, in studies with research animals, the increased dietary intake of choline results in a dose-dependent increase in brain acetylcholine (Cohen and Wurtman, 1976). Cohen and Wurtman suggested that the synthesis of acetylcholine can be controlled by the availability of its required precursors, and that under certain conditions alterations in the level of brain acetylcholine can alter cholinergic transmission.

Our interest has been in the neural mechanisms responsible for the development of kindled seizures (Racine, 1978), and particularly in the neurotransmitters involved. Recent work has demonstrated that seizures can be kindled pharmacologically by the repeated application of a variety of convulsant drugs in initially subconvulsant doses (Goddard, 1969; Mason and Cooper, 1972; Post et al., 1976). Of particular interest is the finding that carbachol, a cholinomimetic, can effectively kindle seizures that are very similar to those kindled using electrical stimulation (Vosu and Wise, 1975). One of us has recently demonstrated that rats kindled with intracerebrally administered carbachol kindle significantly faster when subsequently kindled with electrical stimulation, and vice versa (Cain, 1982). These findings suggest that cholinoceptive neurons may normally participate in electrical kindling. It therefore seemed possible that altered brain levels of acetylcholine produced by alterations in diet might affect the rate at which experimental subjects kindle. In the present study we attempted to alter brain acetylcholine by manipulating the dietary intake of choline, and assessed the effect of this manipulation on the rate of development of electrically kindled seizures.

\section{METHODS}

Male hooded rats weighing between 95 and $100 \mathrm{~g}$ served as subjects. They were randomly separated into cholinedeprived ( $C D ; n=7)$, choline-supplemented $(C S ; n=5)$, and normal chow-fed $(n=5)$ groups. The chow-fed group served as a control for weight changes, and was not used in the kindling phase of the study. The CD subjects were fed a modified commercially available low-choline diet (ICN Pharmaceuticals). This diet had $0.8 \% 1$-cystine and 5\% cholesterol added in order to insure that any available choline would be used in processes other than intraneuronal synthesis of acetylcholine, thus stressing the system maximally. The CS subjects were fed the low-choline diet to which $555 \mathrm{mg} / \mathrm{kg}$ free choline (provided as the chloride salt) and $5 \%$ cholesterol had been added. The chow-fed subjects were given standard Purina lab chow, which contains 400 $\mathrm{mg} / \mathrm{kg}$ free choline (manufacturers analysis). The diets were stored under refrigeration and provided in non-spillable cups. The diets and drinking water were provided ad libitum and the subjects were maintained on the respective diets for the duration of the experiment. For the first 40 days of diet consumption, the amount consumed and the body weights were recorded.

When they weighed between 260 to $300 \mathrm{~g}$ the subjects in the $C D$ and $C S$ groups received implantation of bipolar electrodes into the basolateral amygdala using standard stereotaxic techniques. An additional group of adult male hooded rats $(n=9)$ weighing $300 \mathrm{~g}$ were also implanted with amygdala electrodes. These subjects were fed Purina lab chow, and served as controls for the kindling phase of the 
study. The electrodes were constructed of twisted nichrome wire $127 \mu \mathrm{m}$ in diameter, insulated except at the cut tips. Surgery was carried out under pentobarbital anesthesia.

For kindling the subjects were connected to a polygraph and stimulator by means of a miniature plug, and electroencephalographic activity was recorded before and after stimulation in order to obtain a prestimulation baseline and to record evoked afterdischarge (AD). The kindling stimulation consisted of $1 \mathrm{sec}$ of $60 \mathrm{~Hz}$ biphasic constant current square waves, each $1 \mathrm{msec}$ in duration. The AD threshold was determined in all of the subjects at the outset by applying an initial stimulation of $50 \mu \mathrm{A}$, and increasing the intensity by $25 \mu \mathrm{A}$ on each subsequent stimulation until an $\mathrm{AD}$ was evoked. The subjects were then stimulated at 24-hr. intervals at their individualized AD threshold until they displayed two stage 5 generalized seizures (Racine, 1972).

At the end of testing all subjects were anesthetized and perfused with formol saline; the brain was removed, frozen, and sectioned for verification of the electrode placements. All subjects discussed below had electrode placements in the amygdala. The results were analyzed using analysis of variance, tests of simple main effects and t-tests.

\section{RESULTS}

The CD and CS groups, relative to the chow-fed group, began to lose weight during the first 3 to 4 days on the diets. It seemed possible that the cholesterol had rendered the diets unpalatable, and so it was removed. The subjects in these groups immediately increased their consumption of the diets and gained weight at the same rate as the chow-fed subjects. After 12 days on the diets there was one fatality in the CD group, and three of the subjects in this group stopped gaining weight. In order to avoid further fatalities, these three subjects received a supplement of choline in their drinking water $(1.0 \mathrm{~g} / 1000 \mathrm{cc}$ water $)$ until a gain in body weight was observed, a period of 3 days. During this period these subjects consumed a mean of $52.0 \pm 7.6 \mathrm{cc}$ of water per day. Regression lines were fit to the body weight data in order to describe the rate of growth during the 40 days. The slope of the three lines was similar $(C D$ group $=5.56 ; \mathrm{CS}$ group $=5.85 ;$ chow-fed group $=6.07$ ) .

The AD threshold of the CS group $(70.0 \pm 10.9 \mu \mathrm{A})$ was significantly lower $(p<.01)$ than that of the $C D$ group $(133.3 \pm 15.2 \mu \mathrm{A}$; see Table 1). The AD threshold of the CD group did not differ significantly from that of the chowfed group $(122.2 \pm 16.2 \mu \mathrm{A})$. A two-way analysis of variance yielded a significant interaction between diet and rate of seizure development $(F=2.90 ; p=.0076)$, indicating that the groups diverged in kindling rate. Tests of simple main effects indicated that the chow-fed and CD groups did not differ significantly in their rate of seizure development $(F=2.74 ; p>>.05)$, whereas the $C D$ and $C S$ groups did differ significantly in their rate of seizure development $(F=24.9 ; p<.001)$.

\section{DISCUSSION}

The results of this study indicate that deprivation of dietary choline does not affect the rate of amygdaloid kindling in the rat. In light of the possible role that acetylcholine may play in amygdaloid kindling (Cain, 1983;
TABLE 1

Afterdischarge Threshold and Rate of Amygdaloid Kindling*

\begin{tabular}{|c|c|c|c|c|c|}
\hline Group & $\mathbf{n}$ & AD Threshold & $\mathbf{p}$ & $\begin{array}{l}\text { ADs to the } \\
\text { first generalized } \\
\text { seizure }\end{array}$ & $\mathbf{p}$ \\
\hline CS & 5 & $70.0 \pm 10.9 \mu \mathrm{A}$ & & $8.8 \pm 2.2$ & \\
\hline & 6 & $133.3 \pm 15.2$ & & $12.7 \pm 1.9$ & \\
\hline $\begin{array}{l}\text { chow- } \\
\text { fed }\end{array}$ & 9 & $122.2 \pm 16.2$ & & $11.6 \pm 3.8$ & \\
\hline
\end{tabular}

* Values are mean \pm S.D.

Vosu and Wise, 1975) the lack of an effect of choline deprivation on the rate of kindling may reflect the absence of an effect of choline deprivation on brain acetylcholine levels at the time of kindling. This idea is supported by the results of studies in which it has been shown that long-term deprivation of dietary choline resulted in no deviation from normal levels of brain acetylcholine (Cohen and Wurtman, 1976; Haubrich et al., 1976). Haubrich and his colleagues have interpreted these results as indicating the possible existence of a compensatory mechanism that operates in the long term to maintain normal levels of brain acetylcholine. The existence of such a compensatory mechanism might explain our failure to measure a difference in the rate of kindling between the $C D$ and chow-fed groups. Alternatively, other neurotransmitter systems might be fully capable of supporting electrical kindling of the amygdala even in the presence of abnormally low levels of brain acetylcholine.

The results of this study also indicate that dietary supplementation of choline to levels above normal significantly facilitates the rate of amygdaloid kindling. Studies with animal subjects have shown that such supplementation results in a dose-dependent increase in the level of brain acetylcholine (Cohen and Wurtman, 1976). These results are consistent with previous studies in which acetylcholine has been implicated in amygdaloid kindling. Clinical attempts to increase cholinergic activity in humans by dietary supplementation with choline have resulted in increases in plasma choline levels (Fernstrom, 1981). Our results suggest that supplementation of dietary choline above normal levels might result in an increased susceptibility to epileptic seizures. This could result from either a reduced threshold for seizure or from an increase in the rate of seizure development.

\section{ACKNOWLEDGEMENT}

This research was supported by a grant to D.P. Cain from the Natural Sciences and Engineering Research Council of Canada.

\section{REFERENCES}

Bartus, R.T., Dean, R.L. III, Beer, B. and Lippa, A.S. (1982). The cholinergic hypothesis of geriatric memory dysfunction. Science, 217, 408-417. 
Cain, D.P. (1983). Bidirectional transfer of electrical and carbachol kindling. Brain Res., in press.

Cohen, E.L. and Wurtman, R.J. (1976). Brain acetylcholine: Control by dietary choline. Science, 191, 561-562.

Davis, K.L., Berger, P.A. and Hollister, L.E. (1975). Choline for tardive dyskinesia. N. Eng. J. Med., 293, 152.

Fernstrom, M.H. (1981). Lecithin, choline, and cholinergic transmission. In G.A. Spiller (Ed.) Current Topics in Nutrition and Disease. Vol. 4. Nutritional Pharmacology. A.R. Liss, N.Y., 1981, 5-29.

Goddard, G.V. (1969). Analysis of avoidance conditioning following cholinergic stimulation of amygdala in rats. J. Comp. Physiol. Psychol. Monogr. 68, no. 2, part 2, 1-18.

Haubrich, D.R., Wang, P.F.L., Chippendale, T. and Proctor, E. (1976). Choline and acetylcholine in rats: Effect of dietary choline. J. Neurochem., 27, 1305-1313.
Mason, C.R. and Cooper, R.M. (1972). A permanent change in convulsive threshold in normal and braindamaged rats with repeated small doses of pentylenetetrazol. Epilepsia, 13,663-674.

Post, R.M., Kopanda, R.T. and Black, K.E. (1976). Progressive effects of cocaine on behavior and central amine metabolism in rhesus monkeys: Relationship to kindling and psychosis. Biol. Psychiat., 11, 403-419.

Racine, R.J. (1972). Modification of seizure activity by electrical stimulation: II. Motor seizure. Electroencephalog. Clin. Neurophysiol., 32, 281-294.

Racine, R.J. (1978). Kindling: The first decade. Neurosurg. 3, 234-251.

Vosu, H. and Wise, R.A. (1975). Cholinergic kindling in the rat: Comparison of caudate, amygdala and hippocampus. Behav. Biol., 13, 492-495. 